\title{
Mild environmental intervention in mother-infant interactions reduces social play behavior in rats
}

\author{
Ana Raquel M. Karkow and Aldo B. Lucion \\ Universidade Federal do Rio Grande do Sul, Porto Alegre, RS, Brazil
}

\begin{abstract}
During early life, animals are sensitive to environmental events that may lead to short-term and long-lasting changes in their neurobiology and behavior, which could be related to increased risk for psychopathology. Neonatal handling is an experimental intervention in the mother-infant relationship. Based on previous studies, it is known to decrease rat pups' preference for maternal cues. Handling also reduces social, sexual, and fear behavior in adult animals, which is related to underlying neuroendocrine alterations. One prominent feature of adolescence is the high frequency of social behaviors such as play that appear to be necessary for proper socioemotional development. The objective of the present study was to investigate the effect of repeatedly handling pups on social play behavior during the neonatal period in juvenile Wistar rats. We found that handling consistently decreased pouncing, wrestling, and chasing play behavior on postnatal days (PND) 25, 30, and 35 compared with non-handled juveniles. As expected, sex differences were also found. Consistent with previous studies in infant and adult rats, the neonatal handling procedure also reduced affiliative behaviors in juvenile animals. The precise mechanisms by which this early intervention leads to these alterations in offspring remain to be determined, but the cumulative effects of briefly disrupting the mother-infant relationship that caused the neonatal handling may be one possible explanation. Keywords: early life intervention, neonatal handling, play behavior, social interaction, juvenile rats.
\end{abstract}

Received 13 November 2012; received in revised form 1 March 2013; accepted 9 April 2013. Available online 27 June 2013.

\section{Introduction}

Environmental events during early life may induce long-lasting effects on the phenotypes of animals, program the outcome of several behavioral and neuroendocrine features, and increase the vulnerability to pathology (McGowan \& Szyf, 2010; Claessens, Daskalakis, van der Veen, Oitzl, de Kloet, \& Champagne, 2011; Miller, Chen, \& Parker, 2011). Several experimental approaches have been used to study the long-lasting effects of early life events (Tarantino, Sullivan, \& Meltzer-Brody, 2011; ReebSutherland \& Tang, 2011; Zimmerberg \& Sageser, 2011; Huppertz-Kessler, Poeschl, Hertel, Unsicker, \& Schenkel, 2012). The primary intervention is the

Ana Raquel Menezes Karkow and Aldo Bolten Lucion, Departamento de Fisiologia, Instituto de Ciências Básicas da Saúde, Universidade Federal do Rio Grande do Sul, Sarmento Leite, 500, Porto Alegre, RS, CEP 90050-170, Brazil. Ana Raquel Menezes Karkow and Aldo Bolten Lucion, PPG Neurociencias, Universidade Federal do Rio Grande do Sul, Sarmento Leite, 500, Porto Alegre, RS, CEP 90050-900, Brazil. Aldo Bolten Lucion, PPG Fisiologia, Universidade Federal do Rio Grande do Sul, Sarmento Leite, 500, Porto Alegre, RS, CEP 90050-170, Brazil. Correspondence regarding this article should be directed to: Aldo Bolten Lucion, Sarmento Leite, 500, Porto Alegre, Rio Grande do Sul, Brazil. Phone: +55 513308-3359. Fax: +55 51-3308-3656. E-mail: alucion@ufrgs. br or aldo.lucion@gmail.com separation of pups from their mother. Many mammals, including humans, need to be cared for, nurtured, and protected after birth; otherwise they die. Thus, the role of the mother is crucial for survival. Neonatal handling is considered a mild environmental intervention that involves briefly removing pups from their mother and does not involve pain or fasting (Noschang, Krolow, Arcego, Toniazzo, Huffel, \& Dalmaz, 2012; Veenema, 2012). As a consequence, maternal behavior increases during the period immediately after the pups are returned to the nest (Todeschin et al., 2009). Therefore, part of the effects of the handling procedure appear to be mediated by changes in maternal behavior (Smotherman, Bell, Starzec, Elias, \& Zachman, 1974; Villescas, Bell, Wright, \& Kufner, 1977). Thus, the handling intervention per se or the consequent changes in maternal behavior may exert complex effects on the psychosocial development of the animal.

Previous studies from our laboratory have shown that the handling procedure reduces the pups' preference for maternal cues (Raineki et al., 2009). Later in life, neonatal handling reduces "amicable" social behaviors (Todeschin et al., 2009). Indeed, handling has a major impact on social behaviors in adulthood such as a reduction of sexual behavior (Padoin, Cadore, Gomes, Barros, \& Lucion, 2001). However, other effects of environmental intervention during early life appear to depend on time. For example, attenuation of the 
stress response, which is the core effect of the handling procedure, was not detected in juvenile rats prior to puberty (Padoin et al., 2001; Severino et al., 2004).

Play is the most common social behavior observed in juvenile rats (Meaney \& Stewart, 1981; Thor \& Holloway, 1986; Hotchkiss, Ostby, Vandenbergh, \& Gray, 2003). Play appears to be essential for the development of social behavior (Trezza, Baarendse, \& Vanderschuren, 2010). Considering that the mother-infant relationship shapes social behavior later in life and that previous studies have shown that the neonatal handling procedure reduces social interactions during the neonatal period (Raineki et al., 2009) and adulthood (Todeschin et al., 2009), the present study investigated the effects of neonatal handling from postnatal day (PND) 1 to PND 10 on social play behavior in male and female rats at 25,30, and 35 days of age. We hypothesized that a continuum of deficits in social interaction induced by environmental intervention in the mother-infant interaction would be evident throughout life. Because play behavior is sexually dimorphic (Thor \& Holloway, 1986), possible sexual differences were also analyzed.

\section{Methods}

\section{Subjects}

Pregnant female Wistar rats $(n=36)$ from the breeding colony of the Federal University of Rio Grande do Sul were brought to the colony room in our laboratory. Approximately 7 days before delivery, pregnant rats were housed individually, and the presence of pups was checked twice per day (i.e., at the beginning and end of the light cycle). The day of birth was considered day 0 (zero). On day 1 , the number of pups was culled to eight per dam by removing pups selected by sex to have at least four animals of the same sex for the behavioral recordings.

Animals were maintained on a $12 \mathrm{~h} / 12 \mathrm{~h} \mathrm{light} /$ dark cycle (lights on from 6:00 AM to 6:00 PM) with a room temperature of $22 \pm 1{ }^{\circ} \mathrm{C}$. Water and food (Rodent chow, Nutrilab, Colombo, Brazil) were available ad libitum. All procedures in this study followed the National Institutes of Health Guide for the Care and Use of Laboratory Animals and were approved by the Ethics Committee of Research at the Federal University of Rio Grande do Sul (protocol no. 2007862).

\section{Procedure}

The pups were handled for 1 min per day from PND 1 to 10. Initially, the home cage with the litter and mother was taken to a room next to the animal facility where the light and temperature were similar. The mother was then placed in another cage beside the home cage, and the experimenter gently handled the entire litter simultaneously using both hands and latex gloves. The pups were handled at a distance of $\sim 2 \mathrm{~m}$ from the mother, and the total time of motherinfant separation was $\sim 2 \mathrm{~min}$. This procedure was repeated from PND 1 to 10 during the light period of the daily light/dark cycle. No specific movements along the bodies of the animals were performed; they were simply touched. No apparent harm was inflicted on the pups. After handling, all of the pups were returned to the nest at the same time, and the mother was returned to the home cage. This specific procedure has been previously used (Gomes, Frantz, Sanvitto, Anselmo-Franci, \& Lucion, 1999; Padoin et al., 2001; Severino et al., 2004). The intervention is apparently not physically harmful to the pups, but it interferes with the mother-infant relationship, which appears to be the key factor that explains the long-lasting effects of this mild intervention. In the present study, we did not analyze maternal behavior. However, several reports (de Azevedo, de Souza, Donadio, Lucion, \& Giovenardi, 2010; Hellstrom, Dhir, Diorio, \& Meaney, 2012) showed complex changes in maternal behavior, most notably increased licking after the procedure but also a reduction of nursing behavior.

The pups were divided into two main groups: nonhandled and handled. The non-handled animals were not manipulated by either the researchers or caretakers from PND 1 to 10, and their bedding was changed twice weekly after PND 10. On PND 21, the pups were weaned and housed in same-sex colonies of four littermates. Thirty-six colonies were divided into four groups: non-handled males $(n=9)$, non-handled females $(n=9)$, handled males $(n=9)$, and handled females $(n$ $=9)$. The home cages $(41 \mathrm{~cm}$ length $\times 34 \mathrm{~cm}$ width $\times 24$ $\mathrm{cm}$ height) consisted of transparent polycarbonate boxes that permitted behavioral observation.

Behavior was recorded for the same animals on days 25,30 , and 35 . The behavioral recordings were performed in the home cage and same room where the animals were housed. At each age, the behavior of each rat in the colony was scored during one observation session during the light phase (3:00 PM, session 1) and three observation sessions during the dark phase (6:00 PM, session 2; 8:00 PM, session 3; 9:30 PM, session 4) of the light-dark cycle. During the dark phase, the pups were visualized by faint light from a $25-\mathrm{W}$ red incandescent bulb placed $\sim 1 \mathrm{~m}$ above the cage that was focused obliquely on the center of the cage. An instantaneous focal sampling method was used to record the behavior of the colonies. Using a spreadsheet, an experienced researcher noted the play behavior of the colony engaged at that specific moment. If two play behaviors were displayed at the same moment, then both were recorded. Within each session, the behavior of the four juveniles was scored every $3 \mathrm{~min}$, rendering a total of 100 recordings per colony per day ( 25 recordings per session $\times 4$ sessions per age $=100$ recordings). Thus, for each age timepoint (sessions 1, 2, 3, and 4), the maximum frequency of each behavior was 100 . The data are reported as the averages of the total frequency of each behavior among the colonies of each group.

The following social play behaviors (Meaney \& Stewart, 1981) were recorded: (1) pouncing (i.e., one 
animal solicits the other to play by attempting to nose or rub the nape of the partner's neck), (2) wrestling (i.e., two animals roll and tumble with one another), (3) boxing (i.e., two animals stand upright, facing one another, and make pawing movements toward one another), (4) on-the-back posture (i.e., one animal lies on its back, fully exposing its ventral surface to another animal), (5) chasing (i.e., one animal runs toward another that moves in the opposite direction), and (6) sniffing (i.e., one animal sniffs the anogenital region of another animal).

\section{Statistical analysis}

All results are expressed as the mean \pm standard error of the mean (SEM). A two-way analysis of variance (ANOVA) was used to evaluate play behavior, with sex and handling as factors. When appropriate, the ANOVA was followed by the Bonferroni post hoc test. In all cases, the level of statistical significance was $p<.05$.

\section{Results}

All of the behaviors described in the Methods were recorded, but the following behaviors reached a reliable frequency for the statistical analysis.

\section{Pouncing on PND 25, 30, and 35}

Main effects of handling and sex were found on pouncing behavior in juveniles at the three ages studied (Figure 1). Neonatal handling reduced the frequency of pouncing compared with non-handled animals on PND $25\left(F_{1,33}=37.78, p<.001\right)$, PND $30\left(F_{1,33}=27.36, p<\right.$ $.001)$, and PND $35\left(F_{1,33}=67.80, p<.001\right)$. As expected, males had a higher frequency of pouncing than females on PND $25\left(F_{1,33}=12.08, p<.001\right)$, PND $30\left(F_{1.33}=\right.$ $14.04, p<.001)$, and PND $35\left(F_{1,33}=27.25, p<.001\right)$. No significant interaction between handling and sex was detected on PND $25\left(F_{1,33}=.02\right)$ and PND $30\left(F_{1,33}=\right.$ 41). However, a significant interaction between factors was observed on PND $35\left(F_{1,33}=19.95, p<.001\right)$, in which the effect of handling was more pronounced in males than in females, although the intervention reduced play in both.

\section{Chasing on PND 25, 30, and 35}

Main effects of handling and sex were found on chasing behavior in juveniles at the three ages studied (Table 1). Neonatal handling reduced the frequency of chasing on PND $25\left(F_{1,33}=8.87, p<.01\right)$, PND 30 $\left(F_{1,33}=17.38, p<.001\right)$, and PND $35\left(F_{1,33}=27.99, p\right.$ $<.001)$. With regard to sex differences, males engaged in more chasing behavior than females on PND 25 $\left(F_{1,33}=7.71, p<.01\right), \operatorname{PND} 30\left(F_{1,33}=53.93, p<.001\right)$, and PND $35\left(F_{1,33}=4.40, p<.05\right)$. No significant interaction between handling and sex was detected at any of the ages studied (PND 25, $F_{1,33}=.46$; PND 30, $F_{1,33}=1.06$; PND 35, $F_{1,33}=.53$ ).
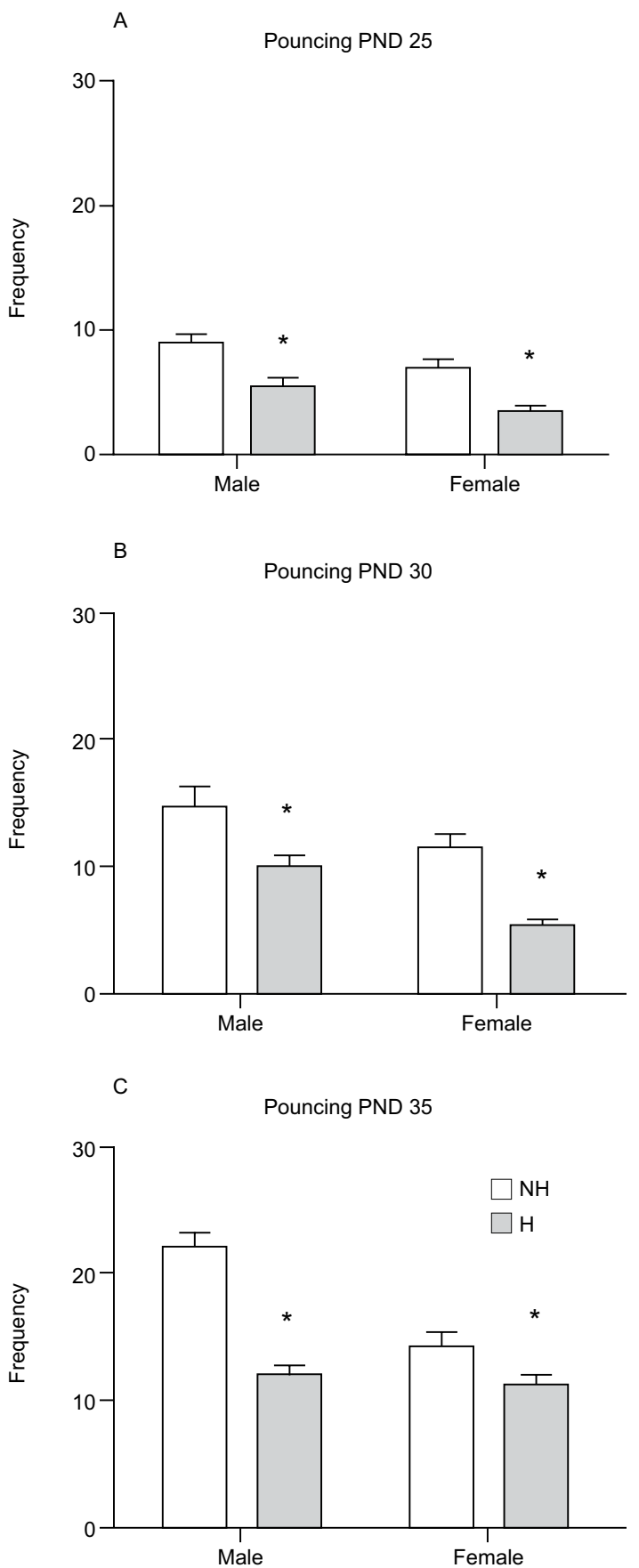

Figure 1. Pouncing on postnatal days (PND) 25, 30, and 35. Mean $( \pm$ SEM) frequencies of pouncing behavior in non-handled $(\mathrm{NH})$ and handled $(\mathrm{H})$ juvenile male and female rats. Two-way ANOVA (handling and sex as factors) showed that neonatal handling (1 min daily manipulation from PND 1 to 10) reduced the amount of pouncing at all ages $(p<.05)$ regardless of sex. Moreover, as expected, males showed an increased frequency of pouncing compared with females $(p<.05)$, independent of the handling intervention. Non-handled males $(n=9)$, non-handled females $(n=9)$, handled males $(n=9)$, and handled females $(n=9)$. ${ }^{*}$ Difference between $\mathrm{H}$ and $\mathrm{NH}$ animals.

\section{Wrestling on PND 25, 30, and 35}

Main effects of handling and sex were found on wrestling behavior in juveniles at the three ages studied (Table 1). Neonatal handling reduced the frequency of wrestling on PND $25\left(F_{1,33}=13.09, p<.01\right)$, PND $30\left(F_{1,33}\right.$ $=7.48, p<.001)$, and PND $35\left(F_{1,33}=7.27, p<.001\right)$. 
Table 1. Mean ( \pm SEM) frequencies of chasing and wrestling in non-handled $(\mathrm{NH})$ and handled $(\mathrm{H})$ juvenile male $(\mathrm{M})$ and female (F) rats on postnatal day (PND) 25, 30, and 35.

\begin{tabular}{|c|c|c|c|c|c|}
\hline Play behavior & & & PND 25 & PND 30 & PND 35 \\
\hline & & & Mean \pm SEM & Mean \pm SEM & Mean \pm SEM \\
\hline \multirow[t]{8}{*}{ Chasing } & $\mathrm{NH}$ & $\mathrm{M}$ & $3.1 \pm .4$ & $4.5 \pm .5$ & $5.7 \pm .8$ \\
\hline & & $\mathrm{F}$ & $1.7 \pm .2$ & $1.8 \pm .2$ & $4.3 \pm .4$ \\
\hline & $\mathrm{H}$ & $\mathrm{M}$ & $1.7 \pm .4^{*}$ & $2.9 \pm .2 *$ & $2.7 \pm .3^{*}$ \\
\hline & & $\mathrm{F}$ & $.8 \pm .3^{*}$ & $.8 \pm .2 *$ & $2.0 \pm .2^{*}$ \\
\hline & $\mathrm{NH}$ & $\mathrm{M}$ & $2.0 \pm .1$ & $2.4 \pm .2$ & $3.3 \pm .2$ \\
\hline & & $\mathrm{F}$ & $1.3 \pm .1$ & $2.1 \pm .2$ & $2.1 \pm .3$ \\
\hline & $\mathrm{H}$ & $\mathrm{M}$ & $1.6 \pm .3^{*}$ & $2.0 \pm .2 *$ & $2.1 \pm .2 *$ \\
\hline & & $\mathrm{F}$ & $1.1 \pm .3^{*}$ & $1.0 \pm .2 *$ & $1.8 \pm .2 *$ \\
\hline
\end{tabular}

Non-handled males $(n=9)$, non-handled females $(n=9)$, handled males $(n=9)$, and handled females $(n=9)$.

*Difference between $\mathrm{H}$ and $\mathrm{NH}$ animals.

The main effect of sex on wrestling was not significant on PND $25\left(F_{1,33}=4.35, p=.05\right)$, but as expected the males showed more rough and tumble play than females on PND $30\left(F_{1,33}=10.18, p<.01\right)$ and PND $35\left(F_{1,33}=7.27\right.$, $p<.01)$. No significant interaction between handling and sex was detected at any of the ages (PND 25, $F_{1,33}=.36$; PND 30, $F_{1,33}=1.87$; PND 35, $F_{1,33}=3.48$ ).

\section{Discussion}

The present results show that the handling procedure consistently decreased social play behavior among peripubertal rat littermates. On PND 25, 30, and 35 , social play behavior in handled male and female rats decreased compared with non-handled rats. We may conclude that the intervention may reduce sociability in pups before puberty. These results complete the temporal analysis of the effects of the neonatal handling procedure on social behavior in rats. Indeed, a previous study (Raineki et al., 2009) showed that pups handled at 7 days of age had a decreased preference for the familiar nest odor. Moreover, in adult rats, the handling intervention during early life decreased social memory, decreased amicable social behavior, increased aggressive behavior (Todeschin et al., 2009), and decreased the preference for a sexually active partner (Raineki, Lutz, Sebben, Ribeiro, \& Lucion, 2012).

Interestingly, rats raised by high-licking mothers exhibited a reduction of social play behavior compared with pups born and reared by low-licking mothers (Parent \& Meaney, 2008; Parent, Del Corpo, Cameron, \& Meaney, 2012). The experimental approaches, however, were different. The present study analyzed the effects of the handling intervention, which is not natural environmental stimulation for rats. In contrast, the other studies described the effects of natural variations in maternal care. However, in both cases, the pups were subjected to high-licking mothers because handling induces a burst in licking behavior (de Azevedo et al.,
2010). A previous study (Aguilar, Caramés, \& Espinet, 2009) showed that neonatal handling may increase the frequency of pinning behavior, provided that the animals were previously socially isolated. In that specific situation of social deprivation, handled rats showed increased social play behavior instead of the decrease described herein. However, in the present study, basal social interaction among juveniles was determined in four daily observation sessions at three different ages and not after social deprivation, which may explain the differences in the results.

Although the actual function of play fighting in social development remains to be established, animals deprived of the opportunity to play during the juvenile period display altered or decreased mating activity (Gerall et al., 1967; Hard \& Larsson, 1968; Gruendel \& Arnold, 1969), decreased affiliative interactions in adulthood (Stewart, Vallentyne, \& Meaney, 1979), and increased agonistic behaviors (Lore \& Flannelly, 1977). Moreover, social play increases c-fos activation in several brain areas such as the periaqueductal gray, ventromedial hypothalamus, and somatosensory cortex, which may indicate the neural basis of these social behaviors in adolescence (Gordon, KollackWalker, Akil, \& Panksepp, 2002). We suggest that the reduction of play induced by the handling procedure may explain the decrease in social non-aggressive behavior (Todeschin et al., 2009) and partner preference (Raineki et al., 2012) in adulthood. Researchers have postulated that the mother-infant relationship could be the basis for future social behavior (Huppertz-Kessler et al., 2012). We may infer that the long-lasting effects of the handling procedure are related to changes in the mother-infant relationship. The present study did not analyze the behavior of the mother, but previous studies from our laboratory (de Azevedo et al., 2010) and others (Villescas et al., 1977; Champagne, Francis, Mar, \& Meaney, 2003) showed an increase in licking behavior immediately after the intervention, and this change in 
maternal behavior was associated with the phenotype of the animal. However, a more detailed analysis showed that the intervention also decreased mother-infant contact by reducing nursing behavior. After the handling procedure, the mother stayed outside the nest and away from the pups more often than mothers whose pups were not handled (Reis, de Azevedo, Alves, \& Lucion, 2011). These changes in maternal behavior could be the basis for later sociability of the offspring.

In the context of previous studies (Raineki et al., 2009, 2012; Todeschin et al., 2009), the present study demonstrated the crucial impact of environmental intervention during early life on the mother-infant relationship in programming social bounds in a gregarious species. We may speculate that neonatal events such as maternal neglect and infant hospitalization or institutionalization could also affect the development of social behaviors in humans.

\section{Acknowledgements}

This research was funded by grants from CNPq, CAPES and PRONEX-FAPERGS no. 008/2009.

\section{References}

Aguilar, R., Caramés, J. M., \& Espinet, A. (2009). Effects of neonatal handling on playfulness by means of reversal of the desire to play in rats (Rattus norvegicus). Journal of Comparative Psychology, 123(4), 347-356.

Champagne, F. A., Francis, D. D., Mar, A., \& Meaney, M. J. (2003). Variations in maternal care in the rat as a mediating influence for the effects of environment on development. Physiology and Behavior, 79(3), 359-371.

Claessens, S. E., Daskalakis, N. P., van der Veen, R., Oitzl, M. S., de Kloet, E. R., \& Champagne, D. L. (2011). Development of individual differences in stress responsiveness: an overview of factors mediating the outcome of early life experiences. Psychopharmacology, 214(1), 141-154.

de Azevedo, M. S., de Souza, F. L., Donadio, M. V. F., Lucion, A. B., \& Giovenardi, M. (2010). Interventions in the neonatal environment in rats and their relationship to behavior in adulthood and maternal behavior. Psychology \& Neuroscience, 3(1), 73-78.

Gerall, H. D., Ward, I. L., \& Gerall, A. A. (1967). Disruption of the male rat's sexual behaviour induced by social isolation. Animal Behaviour, 15(1), 54-58.

Gomes, C. M., Frantz, P. J., Sanvitto, G. L., Anselmo-Franci, J. A., \& Lucion, A. B. (1999). Neonatal handling induces anovulatory estrous cycles in rats. Brazilian Journal of Medical and Biological Research, 32(10), 1239-1242.

Gordon, N. S., Kollack-Walker, S., Akil, H., \& Panksepp, J. (2002) Expression of c-fos gene activation during rough and tumble play in juvenile rats. Brain Research Bulletin, 57(5), 651-659.

Gruendel, A. D., \& Arnold, W. J. (1969). Effects of early social deprivation on reproductive behavior of male rats. Journal of Comparative and Physiological Psychology, 67(1), 123-128.

Hard, E., \& Larsson, K. (1968). Effects of mounts without intromission upon sexual behaviour in male rats. Animal Behaviour, 16(4), 538-540.

Hellstrom, I. C., Dhir, S. K., Diorio, J. C., \& Meaney, M. J. (2012). Maternal licking regulates hippocampal glucocorticoid receptor transcription through a thyroid hormone-serotonin-NGFI-A signalling cascade. Philosophical Transactions of the Royal Society B: Biological Sciences, 367, 2495-2510.

Hotchkiss, A. K., Ostby, J. S., Vandenbergh, J. G., \& Gray, L. E., Jr. (2003). An environmental antiandrogen, vinclozolin, alters the organization of play behavior. Physiology and Behavior, 79(2), $151-156$.

Huppertz-Kessler, C. J., Poeschl, J., Hertel, R., Unsicker, K., \& Schenkel, J. (2012). Effects of a new postnatal stress model on monoaminergic neurotransmitters in rat brains. Brain and Development, 34(4), 274-279.
Lore, R., \& Flannelly, K. (1977). Rat societies. Scientific American, 236(5), 106-111, 113-116.

McGowan, P. O., \& Szyf, M. (2010). The epigenetics of social adversity in early life: Implications for mental health outcomes. Neurobiology of Disease, 39(1), 66-72.

Meaney, M. J., \& Stewart, J. (1981). Neonatal-androgens influence the social play of prepubescent rats. Hormones and Behavior, 15(2), 197-213.

Miller, G. E., Chen, E., \& Parker, K. J. (2011). Psychological stress in childhood and susceptibility to the chronic diseases of aging: Moving toward a model of behavioral and biological mechanisms. Psychological Bulletin, 137(6), 959-997.

Noschang, C., Krolow, R., Arcego, D. M., Toniazzo, A. P., Huffel, A. P., \& Dalmaz, C. (2012). Neonatal handling affects learning, reversal learning and antioxidant enzymes activities in a sexspecific manner in rats. International Journal of Developmental Neuroscience, 30(4), 285-291.

Padoin, M. J., Cadore, L. P., Gomes, C. M., Barros, H. M., \& Lucion, A. B. (2001). Long-lasting effects of neonatal stimulation on the behavior of rats. Behavioral Neuroscience, 115(6), 1332-1340.

Parent, C. I., Del Corpo, A., Cameron, N. M., \& Meaney, M. J. (2012). Maternal care associates with play dominance rank among adult female rats. Developmental Psychobiology, in press.

Parent, C. I., \& Meaney, M. J. (2008). The influence of natural variations in maternal care on play fighting in the rat. Developmental Psychobiology, 50, 767-776.

Raineki, C., de Souza, M. A., Szawka, R. E., Lutz, M. L., de Vasconcellos, L. F., Sanvitto, G. L., Izquierdo, I., Bevilaqua, L. R., Cammarota, M., \& Lucion, A. B. (2009). Neonatal handling and the maternal odor preference in rat pups: Involvement of monoamines and cyclic AMP response element-binding protein pathway in the olfactory bulb. Neuroscience, 159, 31-38.

Raineki, C., Lutz, M. L., Sebben, V., Ribeiro, R. A., \& Lucion, A. B. (2012). Neonatal handling induces deficits in infant mother preference and adult partner preference. Developmental Psychobiology, in press.

Reeb-Sutherland, B. C., \& Tang, A. C. (2011). Dissociation between neonatal novelty-induced preferential maternal care and enhancement in cognitive, social, and emotional functions. Behavioural Brain Research, 224(2), 318-325.

Reis, A. R., de Azevedo, M. S., Alves, M. B., \& Lucion, A. B. (2011). Efeito da manipulação neonatal sobre o vínculo mãe-filhote. In: VII Congresso Brasileiro de Cérebro Comportamento e Emoções, Gramado-RS. Revista Eletrônica do CBCCE.

Severino, G. S., Fossati, I. A. M., Padoin, M. J., Gomes, C. M., Trevizan, L., Sanvitto, G. L., Franci, C. R., Anselmo-Franci, J. A., \& Lucion, A. B. (2004). Effects of neonatal handling on the behavior and prolactin stress response in male and female rats at various ages and estrous cycle phases of females. Physiology and Behavior, 81, 489-498.

Smotherman, W. P., Bell, R. W., Starzec, J., Elias, J., \& Zachman, T. A. (1974). Maternal responses to infant vocalizations and olfactory cues in rats and mice. Behavioral Biology, 12(1), 55-66.

Stewart, J., Vallentyne, S., \& Meaney, M. J. (1979). Differential effects of testosterone metabolites in the neonatal period on open-field behavior and lordosis in the rat. Hormones and Behavior, 13(3), 282-292.

Tarantino, L. M., Sullivan, P. F., \& Meltzer-Brody, S. (2011). Using animal models to disentangle the role of genetic, epigenetic, and environmental influences on behavioral outcomes associated with maternal anxiety and depression. Frontiers in Psychiatry, 2, 44.

Thor, D. H., \& Holloway, W. R., Jr. (1986). Social play soliciting by male and female juvenile rats: Effects of neonatal androgenization and sex of cagemates. Behavioral Neuroscience, 100(2), 275-279.

Todeschin, A. S., Winkelmann-Duarte, E. C., Jacob, M. H. V., Aranda, B. C. C., Jacobs, S., Fernandes, M. C., Ribeiro, M. F. M., Sanvitto, G. L., \& Lucion, A. B. (2009). Effects of neonatal handling on social memory, social interaction, and number of oxytocin and vasopressin neurons in rats. Hormones and Behavior, 56, 93-100.

Trezza, V., Baarendse, P. J. J., \& Vanderschuren, L. J. M. J. (2010). The pleasures of play: Pharmacological insights into social reward mechanisms. Trends in Pharmacological Sciences, 31, 463-469.

Veenema, A. H. (2012). Toward understanding how early-life social experiences alter oxytocin- and vasopressin-regulated social behaviors. Hormones and Behavior, 61(3), 304-312.

Villescas, R., Bell, R. W., Wright, L., \& Kufner, M. (1977). Effect of handling on maternal behavior following return of pups to the nest. Developmental Psychobiology, 10(4), 323-329.

Zimmerberg, B., \& Sageser, K. A. (2011). Comparison of two models of maternal separation on juvenile social behavior. Frontiers in Psychiatry, 2, 39. 
